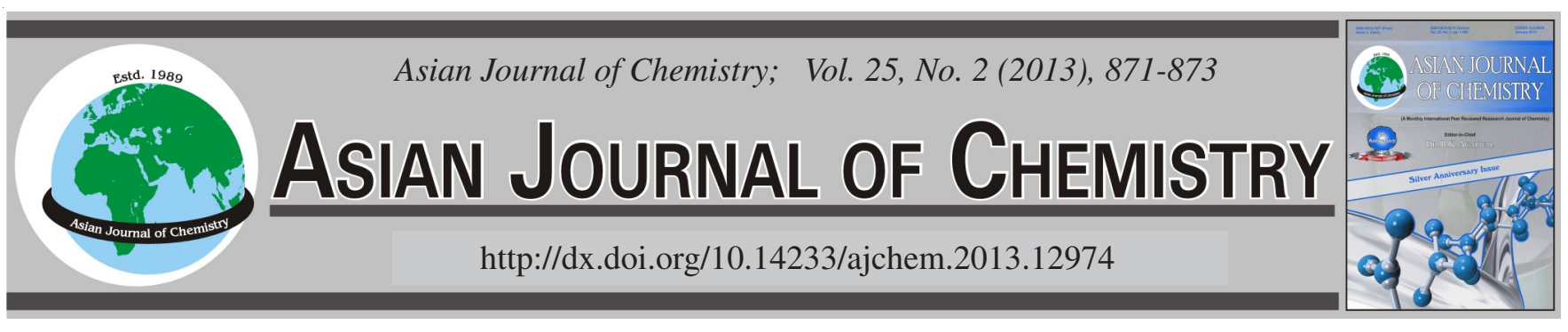

\title{
Preparation of Pyrolytic Carbon Coating from Acetylene by Cold Wall Chemical Vapour Deposition Process
}

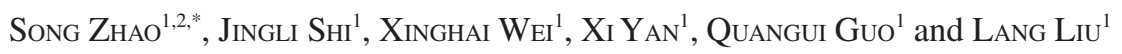

${ }^{1}$ Key Laboratory of Carbon Materials, Institute of Coal Chemistry, Chinese Academy of Science, Taiyuan 030001, P.R. China ${ }^{2}$ Graduate University of the Chinese Academy of Sciences, Beijing 100039, P.R. China

*Corresponding author: Fax: +86 351 4083952; Tel: +86 351 4083952; E-mail: zsbird1223@yahoo.com.cn

\begin{abstract}
Pyrolytic carbon coatings from acetylene were deposited on carbon monofilaments at different temperatures by cold wall chemical vapour deposition equipment. The morphology and microstructure of coatings were investigated by scanning electron microscopy and Raman spectroscopy. The results indicate that the increase of temperature from 1273 to $1773 \mathrm{~K}$ promotes the crystallization of pyrolytic carbon. Following the "particle-filler" model of carbon formation, it can be explained that the increase of temperature is famous for the elimination of amorphous carbon and crystallization of pyrolytic coating through the inhibition of formation of small linear hydrocarbons in the gas phase.

Key Words: Pyrolytic carbon, Monofilaments, Chemical vapour deposition.
\end{abstract}

\section{INTRODUCTION}

Compared with tungsten wire, the carbon filament has lower density and can avoid detrimental reactions between the substrate and coating ${ }^{1,2}$. Thus, carbon monofilaments are often used as the substrate to fabricate advanced $\mathrm{SiC}$ fibers by chemical vapour deposition (CVD) ${ }^{3-5}$. The CVD-SiC fibers with carbon core have outstanding properties at high temperatures and have been eagerly sought for use in the aerospace field $^{6-10}$.

It has been reported that before the $\mathrm{SiC}$ was deposited, the carbon monofilament was usually coated with a thin layer of pyrolytic carbon (PyC) providing a capacity to absorb the effect of the thermal expansion mismatch between the carbon core and the $\mathrm{SiC}$ coating ${ }^{11-14}$. However, the investigation about of pyrolytic carbon coating deposited on the carbon monofilament was hardly found.

For a better understanding of the CVD process and accordingly of the improvement of the filament properties, research of the deposition mechanism and the interface between the carbon core and pyrolytic carbon coating is necessary. Though the deposition mechanism of pyrolytic carbon coating in a hot wall reactor has been studied greatly ${ }^{15-19}$, the study of pyrolytic carbon deposited on carbon monofilaments by cold wall chemical vapour deposition in atmospheric pressure has not yet been reported. In the present experiment, the pyrolytic carbon coating on carbon fibers was prepared by using acetylene as the precursor in a cold wall reactor. The effect of deposition temperature on the microstructure of the pyrolytic carbon coating was discussed.

\section{EXPERIMENTAL}

The laboratory-scale reactor for the chemical vapour deposition on a static monofilament is shown in Fig. 1. The pitch based carbon filament was fed into the reactor from upper end and it was resistance heated by applying direct current through mercury contacts. The coating was carried out in a cold-wall reactor consisting of a vertical glass tube ( $\mathrm{L}$ $=540 \mathrm{~mm}, \mathrm{~d}=30 \mathrm{~mm}$ ) connected to gas inlet/outlet flanges at both ends (top and bottom). Acetylene was used as the precursor for depositing pyrolytic carbon coating. The temperature of the filament was adjusted by the power output.

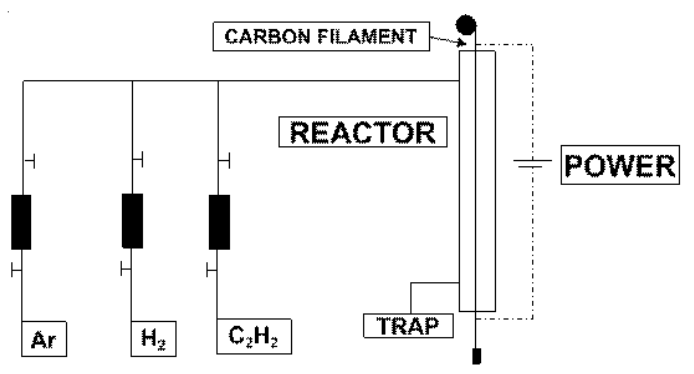

Fig. 1. Schematic diagram of the typical CVD apparatus used for PC coating on carbon monofilament. 
General procedure: The pyrolytic carbon coating was deposited on the carbon monofilament at temperatures from 1273 to $1773 \mathrm{~K}$ using acetylene as a source material and $\mathrm{H}_{2}$ as a carrier gas. The gases were kept contant: $\mathrm{H}_{2} 1 \mathrm{~L} / \mathrm{min}, \mathrm{C}_{2} \mathrm{H}_{2}$ $200 \mathrm{~mL} / \mathrm{min}$. The deposition time of every sample was $1 \mathrm{~min}$.

Detection method: The surface temperature was measured with a high-resolution bichromatic pyrometer (Ircon Mirage). The morphology and the microstructure of the filaments were characterized with a field emission gun scanning electron microscope (FEG-SEM) (NOVA NANOSEM430, FEI). RMS analyses were carried-out at room temperature in a backscattering geometry using the $532 \mathrm{~nm}$ line of an Ar laser as the excitation source with a power of $3 \mathrm{~mW}$ focused to a $1 \mu \mathrm{m}$ diam spot size through an optical microscope (100X). Spectra were obtained at the longitudinal surface of filaments.

\section{RESULTS AND DISCUSSION}

The morphology of pyrolytic carbon coatings deposited on carbon monofilaments were observed by SEM. Fig. 1a-f are the typical SEM images of transverse section of pyrolytic carbon coatings deposited at different temperatures, respectively. It can be seen from Fig. 2a-b that the coating deposited at low temperature is smooth and dense. When the deposition temperature increases (Fig. 2c-f), the morphology of coating becomes rough and several layers appear. It can be seen obviously that the pyrolytic carbon grows laminar by laminar in the pattern of the curved surface. From the microscopy of Fig. 2e, it can be concluded that the laminar microstructure has great effect on the crack deflection.

The Raman spectrum of the pyrolytic carbon coatings deposited at different temperature show a typical polycrysta- lline graphite structure with the $\mathrm{D}$ band (for disorder) at 1365 $\mathrm{cm}^{-1}$ and the $\mathrm{G}$ band (for graphite) at $1580 \mathrm{~cm}^{-1}$ (Fig. 3). The intensity ratio $I_{D} / I_{G}$ and the full widths at half maximum (FWHM) of the D and the G bands have been widely used to characterize the degree of in-plane crystallinity and the crystallite size of primary graphitic domains in carbons.

The $I_{D} / I_{G}$ ratio $(R)$ and the $F W H M$ of the $G$ and the $D$ bands of PyC coatings were determined and are presented in Table-1. When the deposited temperature increased from 1273 to $1673 \mathrm{~K}$, the value of $\mathrm{R}$ was decreased from 1.24-0.90 and the FWHM of the G band became narrower. The FWHM intensity of the $\mathrm{G}$ band has been correlated to the level of graphitization of carbon samples ${ }^{20}$. Additionally, it has been previously found empirically that the ratio $\mathrm{I}_{\mathrm{D}} / \mathrm{I}_{\mathrm{G}}$ is inversely proportional to the in-plane "crystal size" (La) which would be better described as the diameter of a coherent domain for lattice fringes on carbon samples ${ }^{21}$. Thus, the results indicate that larger in-plane crystallites and a higher degree of order of pyrolytic carbon are deposited when the deposition temperature increases.

Based on the analysis above, it can be indicated that the microstructure of pyrolytic carbon coating from acetylene is a function of the temperature of deposition. Lieberman et al. ${ }^{22,23}$ suggested that the value of the $\mathrm{C}_{2} \mathrm{H}_{2} / \mathrm{C}_{6} \mathrm{H}_{6}$ ratio in the gas phase

\begin{tabular}{cccc}
\multicolumn{5}{c}{ TABLE-1 } \\
\multicolumn{4}{c}{$\begin{array}{c}\text { RMS PARAMETERS FOR THE SURFACE } \\
\text { OF THE PyC COATINGS }\end{array}$} \\
\hline $\mathrm{T}(\mathrm{K})$ & $\mathrm{I}_{\mathrm{D}} / \mathrm{I}_{\mathrm{G}}$ & $\mathrm{FWHM}_{\mathrm{G}}$ & $\mathrm{FWHM}_{\mathrm{D}}$ \\
\hline 1273 & 1.24 & 83.7 & 76.9 \\
1473 & 1.13 & 67.1 & 65.8 \\
1673 & 0.90 & 58.8 & 87.3 \\
\hline
\end{tabular}
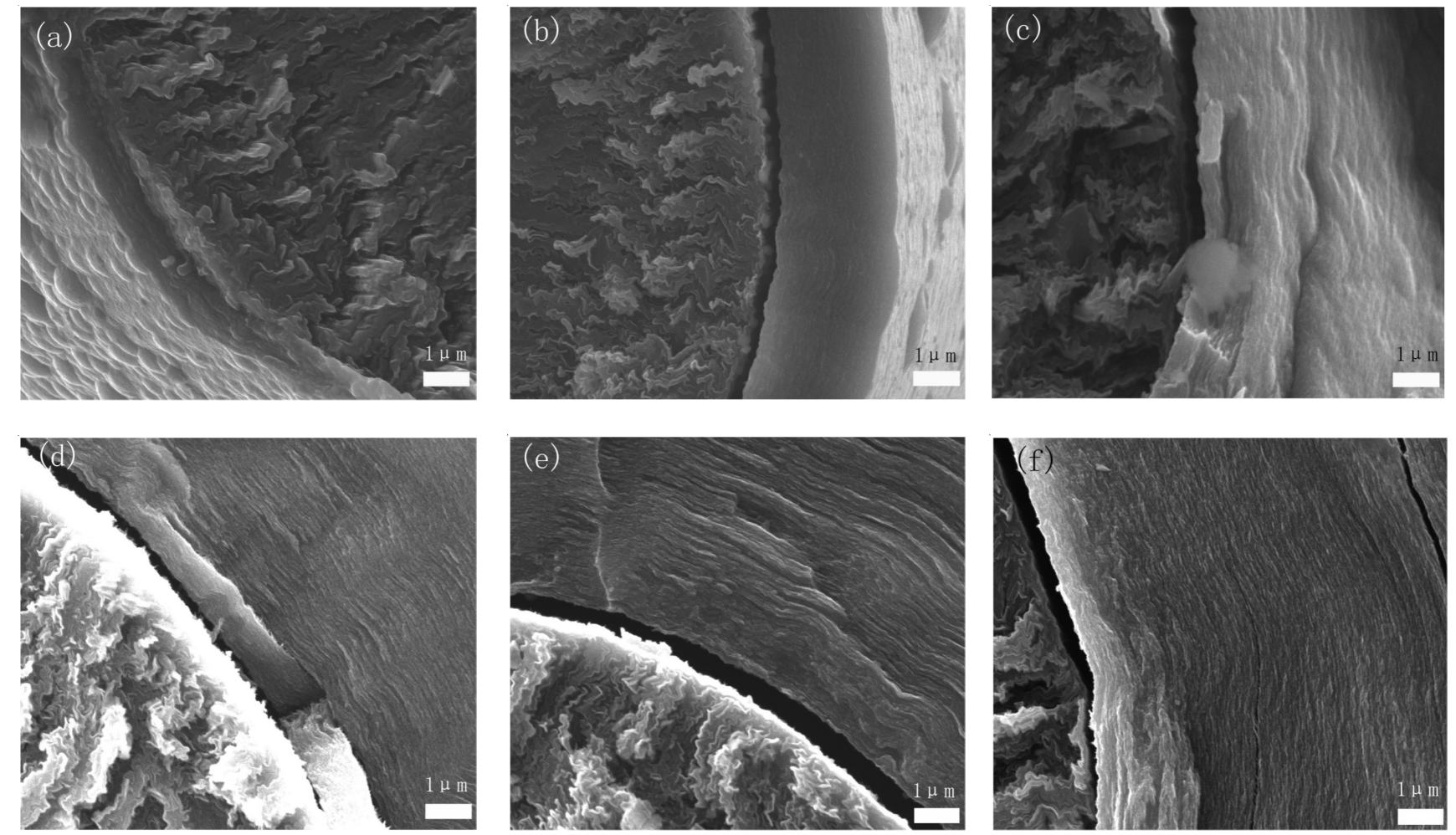

Fig. 2. SEM micrographs of the pyrolytic carbon coating deposited for 1 min on carbon monofilaments at different temperatures. (a) $1273 \mathrm{~K}$, (b) $1373 \mathrm{~K}$, (c) $1473 \mathrm{~K}$, (d) $1573 \mathrm{~K}$, (e) $1673 \mathrm{~K}$, (f) $1773 \mathrm{~K}$ 


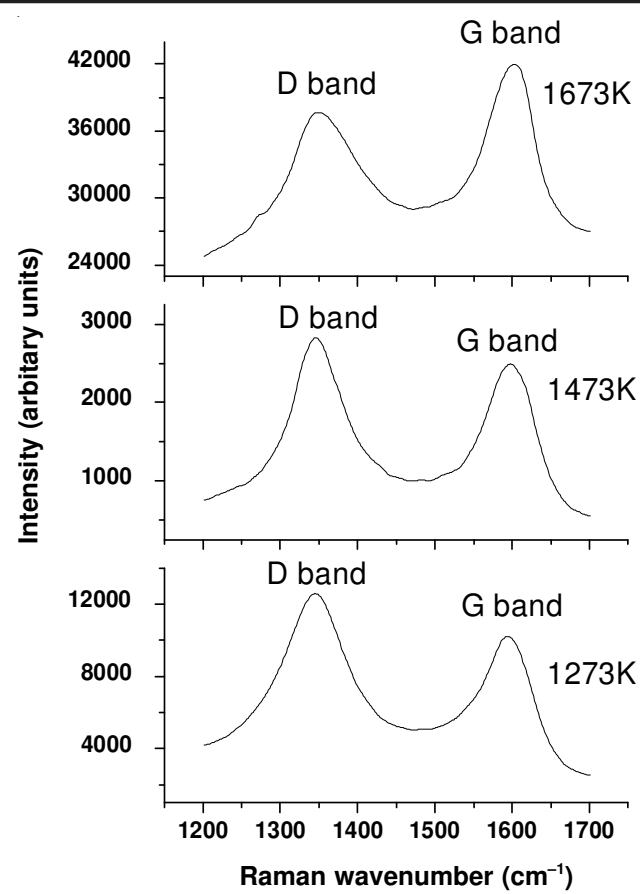

Fig. 3. RMS profile of the pyrolytic carbon coating deposited different temperature

affects the microstructure of pyrolytic carbon during the deposition process. Following the "particle-filler" model of carbon formation $^{24,25}$, it is able to understand the significant influence of the deposition temperature on the evolution of the microstructure of pyrolytic carbon deposited in the cold wall chemical vapour deposition. In the "particle-filler" model, aromatic hydrocarbons are the molecular particles and small linear hydrocarbons, especially ethene, are the molecular filler. It was indicated by Zhang et al. ${ }^{24,25}$ that the filler is mainly necessary to close the open structures resulting from aryl-aryl combination reactions and thus form planar, fully condensed structures. According to the particle-filler model of the carbon texture formation, based on the growth mechanism and discussed in detail in the previous papers ${ }^{24,25}$, small aromatic hydrocarbons besides small linear hydrocarbons with ethene as the major component, are necessary to form a hightextured carbon. In present work, it can be concluded that increase of deposition temperature from 1273 to $1773 \mathrm{~K}$ is beneficial for the formation of optimum ratio between small aromatic hydrocarbons as the molecular particles and small linear hydrocarbons as the molecular filler. The small aromatic hydrocarbons are prone to form graphite crystal while small linear hydrocarbons are used to form amorphous carbon. Thus, the increase of temperature is for the elimination of amorphous carbon and crystallization of pyrolytic coating through the inhibition of formation of small linear hydrocarbons in the gas phase.

\section{Conclusion}

The increase of deposition temperature from 1273 to $1773 \mathrm{~K}$ promotes the crystallization of pyrolytic coating from acetylene by cold wall chemical vapour deposition process. Following the "particle-filler" model of carbon formation, it can be explained that the increase of temperature is famous for the elimination of amorphous carbon and crystallization of pyrolytic coating through the inhibition of formation of small linear hydrocarbons in the gas phase.

\section{REFERENCES}

1. A.L. Burykina, T.Y. Kosolapova, Y.V. Dzyadykevich, É.V. Prilutskii and V.V. Gorskii, Powder Metall. Met. Ceram., 12, 223 (1973).

2. H.P. Martin, E. Müller and U. Dachselt, J. Mater. Sci., 34, 2665 (1999).

3. Y.L. Petitcorps, M. Lahaye, R. Pailler and R. Naslain, Comp. Sci. Technol., 32, 31 (1988).

4. S.R. Nutt and F.E. Wawner, J. Mater. Sci., 20, 1953 (1985).

5. C.A. Lewinsohn, L.A. Giannuzzi, C.E. Bakis and R.E. Tressler, J. Am. Ceram. Soc., 82, 407 (1999).

6. C.H. Andersson and R. Warren, Compos., 15, 16 (1984).

7. P. Deodati, R. Donnini, R. Montanari and C. Testani, Mater. Sci. Eng. A, 521-522, 318 (2009).

8. C.-M. Huang, D. Zhu, Y. Xu, T. Mackin and W.-M. Kriven, Mater. Sci. Eng. A, 201, 159 (1995).

9. R.A. Shatwell, Mater. Sci. Eng. A, 259, 162 (1999).

10. Y.Q. Yang, H.J. Dudek, J. Kumpfert and A. Werner, Scripta Mater., 44, 2531 (2001).

11. X.J. Ning and P. Pirouz, J. Mater. Res., 6, 2234 (1991).

12. J. Kim, S. Tlali, H.E. Jackson, J.E. Webb and R.N. Singh, J. Appl. Phys., 82, 407 (1997).

13. G. Chollon, R. Naslain, C. Prentice, R. Shatwell and P. May, J. Eur. Ceram. Soc., 25, 1929 (2005).

14. P. A. Siemers, R.L. Mehan and H. Moran, J. Mater. Sci., 23, 1329 (1988).

15. S. Jasienko and J. Machnikowski, Carbon, 19, 199 (1981).

16. A. Becker and K.J. HUttinger, Carbon, 36, 201 (1998).

17. O. Haibo, L. Hejun, Q. Lehua, L. Zhengjia, W. Jian and W. Jianfeng, Carbon, 46, 1339 (2008).

18. V.D. Pauw, J. Hawecker, R. Schneider, W. Send, X.L. Wang and D. Gerthsen, Carbon, 46, 236 (2008)

19. P. Silenko, A. Shlapak and V. Afanas'ev, Inorg. Mater., 42, 246 (2006).

20. F. Tuinstra and J.L. Koengi, J. Chem. Phys., 53, 1126 (1970).

21. E. LÓpez-Honorato, P.J. Meadows and P. Xiao, Carbon, 47, 396 (2009).

22. M. Lieberman and H. Pierson, Carbon, 12, 233 (1974).

23. H. Pierson and M. Lieberman, Carbon, 13159 (1975).

24. W. Zhang, Z. Hu and K. Hüttinger, Carbon, 40, 2529 (2002).

25. W. Zhang and K. Hüttinger, Carbon, 41, 2325 (2003). 